\title{
Knowledge and Attitude concerning use of Intrauterine Contraceptive Device among Women attending Family Planning at Makambako RCH in Njombe-Tanzania
}

\author{
Samson Peter Mvandal 1*, Godfrey Lupoly², Joseph Nhandi2, \\ ${ }^{1}$ Department of Health Sciences \& Public Health, PIM Foundation, Tanzania. ${ }^{2}$ Catholic University of Health and \\ allied sciences
}

\begin{abstract}
Background: Intrauterine device is a modern contraceptive method used in family planning process, it prevents conception (pregnancy) and it has duration of 12years. There some women of reproductive age who don't use this method, which necessitates our concern to why they don't use it. The aim of this study is to explore the knowledge and attitude toward utilization of IUCD as family planning method among women attending at Makambako RCH.

Methods: A descriptive cross-sectional quantitative study was used to assess knowledge and attitude concerning use of intrauterine contraceptive device among 384 women of reproductive age. Random sampling was conducted in which every individual had an equal chance to be selected and structured self-administered questionnaire were used to collect data. Data was entered to Microsoft excel and then exported to SPSS version 20.0 for further analysis.
\end{abstract}

Results: Findings of the study about $333(86.7 \%)$ respondents had knowledge on IUD while 51 $(13.3 \%)$ they lack knowledge on IUD and they agreed it helps to prevent unwanted pregnancies and they heard it from social media like radio and television, health care providers, friends and school. About $46(12 \%)$ of the respondents had positive attitude and used IUD method of family planning, and they got influence of using IUD from health care providers, $82(21.4 \%)$ got influence of using IUD from their partners and 27 (7.0\%) influenced to use IUD due to the side effects of other family planning methods like Depo Provera and pills. 25 (5.7\%) were not influenced by anyone to use IUD as family planning method. While $338(88.0 \%)$ participants had negative attitude on IUD method and had never used IUD as family planning method.

Conclusion: The findings show that IUD usage was found to be poor and majority of them they didn't prefer it, despite of having less complications.

Keywords: Attitude, Family planning, knowledge, IUCD, Contraceptive, Reproductive

${ }^{1}$ Corresponding author: samsonpim@gmail.com 


\section{INTRODUCTION}

The intrauterine device (IUD) is a long term reversible contraceptive method that is suitable for women of reproductive ages and represents the most cost-effective reversible method for preventing unwanted pregnancies ,it is one of the most highly effective, convenient and widely used family planning (FP) methods in some parts of the world. ${ }^{[1]}$

A study done in USA 2013, prior studies of women's knowledge about IUCD it indicated significant discrepancies between the respondent's perception of IUCD and actual IUCD characteristics, overall knowledge about the method was poor. ${ }^{[2]}$ Study done in primary care family planning clinics in Cape Town showed that the knowledge of the IUCD as the contraceptive method was very poor, despite its availability it was underused and not a preferred method to prevent pregnancy, shows that $41 \%$ of women had heard about this method but that only $4 \%$ had ever used it. ${ }^{[3]}$

The study done in South Africa showed that there was lack of knowledge among the participants in the study regarding IUCD; therefore, despite the availability of the IUCD in SA clinics and hospitals, its uptake was poor. Awareness of this method seemed to have improved over the past few years but the knowledge was considerably lacking. ${ }^{[4,5]}$

A study done in South west Ethiopia 2016, women of reproductive age who had knowledge on long lasting family planning methods about $59.25 \%$ did not have knowledge that IUCD don't interfere with sexual intercourse and can prevent pregnancy for 12 years, about $34.9 \%$ of women had negative attitudes toward the use of IUD as family planning method as compared to study done in Mekele 53.6\% participants had negative attitude regarding IUCD. ${ }^{[6]}$

A study conducted in Rwanda, showed that among women of childbearing age in a rural setting, the level of knowledge of the method and the use rate was low, more than half of the participants $(56.5 \%)$ had low level of knowledge concerning the method, furthermore use rate of the method ranged from $6.5 \%-25.5 \%$ among women with low and high level of knowledge respectively, the study showed that religious domination appeared to have a statistically significant association on the use of the method whereby women in the Catholic membership were more likely to report use of the method. ${ }^{[7]}$

$$
\text { A study conducted in Shinyanga }
$$
Tanzania, showed that among women of 
childbearing age in a rural setting, the level of knowledge of the method and the use rate was low. The most important determinants of using the method was observed to be level of knowledge of the method, religious affiliation and discussion of family planning issues among partners. ${ }^{[8]}$ Therefore the aim of this study is to assess the level of knowledge and attitude on the use of IUCD method of contraceptive among women attending family planning at Makambako RCH in NjombeTanzania.

\section{MATERIALS AND METHODS}

The research design was a descriptive crosssectional study.

\section{Study Area}

Makambako is a medium-sized town and ward in the Njombe Region of the Tanzania Southern Highlands, located roughly 40 miles north of Njombe city by road. It is located at junction of the roads between Njombe, Iringa, and Mbeya. Its population according to the 2002 Tanzanian census is $51,049 .{ }^{[9]}$ The study was conducted at Makambako $\mathrm{RCH}$ and data was collection within one month.

\section{Study population}

The study included all women of reproductive age (15-49) years, seeking for family planning services at Makambako RCH

\section{Inclusion Criteria}

This study included all women of reproductive age 15-49 years who attended family planning at Makambako $\mathrm{RCH}$ and who were willing to participate were included.

\section{Exclusion Criteria}

All women of reproductive age 15-49 years who refuse to participate in the study were excluded.

\section{Study design and Sampling}

The study was designed to assess the level of knowledge and attitude on the use of IUCD method of contraceptive among women attending family planning at Makambako $\mathrm{RCH}$ in Njombe region southern highland of Tanzania and a simple random technique used whereby every individual had an equal chance to be selected and also questionnaires used.

\section{Methods of data collections}

Data was collected from the participants through structured self-administered Questionnaire prepared in English and Swahili language and was used to obtain information from women of reproductive age (15-45 years).

\section{Statistical analysis}

The data analysis was planned to include descriptive and inferential statistics; data were 
entered into Microsoft excel and then exported to Statistical Package for Social Sciences software (SPSS version 20.0) for further analysis and presented on the percentages and table. The analysis of strength of relationships between categorical variables were conducted using the Chisquare test. A p-value of $<0.05$ was considered to be statistically significant.

\section{Ethical consideration}

Clearance obtained from joint CUHAS-BMC research and ethics review committee. Individual consent was considered and confidentiality was guaranteed. No participant name filled in the form to ensure confidentiality.

\section{RESULTS}

\subsection{Socio-demographic characteristics}

Table 1: Age groups of women of reproductive age (15-45) at Makambako RCH

\begin{tabular}{lcccc}
\hline & Frequency & Percent & Valid \% & Cumulative \% \\
\hline 15-25 years & 216 & 56.3 & 56.3 & 56.3 \\
25-35 years & 142 & 37.0 & 37.0 & 93.2 \\
36-45 years & 26 & 6.8 & 6.8 & 100.0 \\
\hline
\end{tabular}

\subsection{Knowledge on the usage of IUD method of family planning}

Out of $384(100 \%)$ participants who responded to the questionnaires, about $333(86.7 \%)$ respondents knew the correct definition of IUD as a device inserted in a woman's uterus to prevent pregnancy and the method used to insert, 51 (13.3\%) respondents didn't know what IUD meant for. (see Table 2)

Table 2: knowledge on IUD among women of reproductive age at Makambako RCH

\begin{tabular}{lcccc}
\hline & Frequency & Percent & Valid \% & Cumulative \% \\
\hline $\begin{array}{l}\text { Device inserted in a women's } \\
\text { uterus to prevent pregnancy }\end{array}$ & 333 & 86.7 & 86.7 & 86.7 \\
I don't know & 51 & 13.3 & 13.3 & 100.0 \\
\hline
\end{tabular}


Table 3: Source of knowledge on IUD among women of reproductive age at Makambako $\mathrm{RCH}$

\begin{tabular}{lcccc}
\hline & Frequency & Percent & Valid \% & Cumulative \% \\
\hline Media & 16 & 4.2 & 4.2 & 4.2 \\
Provider & 221 & 57.6 & 57.6 & 61.7 \\
Peer & 93 & 24.2 & 24.2 & 85.9 \\
School & 4 & 1.0 & 1.0 & 87.0 \\
I don't know & 50 & 13.0 & 13.0 & 100.0 \\
\hline
\end{tabular}

\subsection{Attitude and utilization of IUD method of family planning}

Table 4: Prevalence of using IUD as family planning method among women of reproductive age at Makambako $\mathrm{RCH}$

\begin{tabular}{lcccc}
\hline & Frequency & Percent & Valid \% & Cumulative \% \\
\hline Currently used & 31 & 8.1 & 8.1 & 100.0 \\
Previously used & 15 & 3.9 & 3.9 & 91.9 \\
Never used & 338 & 88 & 88 & 88 \\
\hline
\end{tabular}

Table 5: Attitude towards IUD method in family planning among women of reproductive age at Makambako $\mathrm{RCH}$

\begin{tabular}{lcccc}
\hline & Frequency & Percent & Valid \% & Cumulative \% \\
\hline Positive attitude & 128 & 33.3 & 33.3 & 33.3 \\
Negative attitude & 161 & 41.9 & 41.9 & 75.3 \\
I don't know & 95 & 24.7 & 24.7 & 100.0 \\
\hline
\end{tabular}

\section{DISCUSSION}

Findings from the study provided the frame work into knowledge and attitude towards IUD usage as among the methods in family planning within the study area. In the study about $333(86.7 \%)$ respondents had knowledge on IUD while $51(13.3 \%)$ they lack knowledge on IUD and they agreed it helps to prevent unwanted pregnancies and they 
heard it from social media like radio and television, health care providers, friends and school and this seems somehow comparable with the study done in Texas 1992 and in Sub -Saharan Africa 2011. ${ }^{[10,11]}$

About $46(12 \%)$ of the respondents had positive attitude on IUD method of family planning while $338(88.0 \%)$ participants had negative attitude on IUD method of family planning due to the following reasons as factors that hinders the IUD usage as follows, woman get pain during sexual intercourse, stomach perforation, uterine cancer, woman can get pregnancy even though IUD is insitu, it can cause infertility, IUD can get out any time and this seems to be comparable with the study done 2003 in India. ${ }^{[12]}$

In this study the knowledge on IUD was found to be high among the women though the use of IUD method was low also discussing of family planning choice with partner in this study was not found to be significant in the uptake of IUD. About $63.8 \%$ of women reported that they usually discuss their FP choice with their partner but this didn't influence the uptake of IUD as compared to the study done in Vietnam found out that $90 \%$ of women made decision regarding FP choice with their partner but it didn't affect the uptake of the device. ${ }^{[13]}$ The study also showed uptake of IUD was found to be $8.1 \%$ due to negative attitude therefore uptake of IUD is very low as compared to the study done in Kenya, documented that the uptake of IUD was low (4\%) and it was due to limited availability of commodities and lack of supportive policies. ${ }^{[14,15]}$

Utilization of IUD as the method for family planning, from this study about $88 \%$ respondents had never used, though they have knowledge about the method but because they possess negative attitudes, they don't prefer this method, as compared to the study done In Dar es salaam, Tanzania. ${ }^{[16]}$ documented that $(63.2 \%)$ of the participants who had not used IUCD were probed on the reasons for failing to adopt the IUD method such as fear of the procedure was the most frequently mentioned reason for not using IUD, one can conceive when using IUCD and baby born with the device embedded in the body, it might travel to other body organs, it might spread infections to other parts of the body, it causes infertility and it can cause cancer $^{[17]}$ 


\section{CONCLUSIONS}

The results of this study show the gulf which exists between women's perceptions of IUCD usage and formal medical knowledge. Studies on other places around the world may reveal similar discrepancies. A deeper awareness must be provided especial outreach, family planning education, seminars so as to strengthen and encourage more women to use IUCD as family planning method.

\section{FUNDING}

This research received no external funding

\section{CONFLICTS OF INTEREST.}

The author declares no conflict of Interests exist.

\section{ACKNOWLEDGEMENTS.}

The authors acknowledge the PIM foundation for giving us support with various research materials. Thanks to Kudra Mponzi, Deo Njowoka, Dr. Peter Lawrence for their support. The Wanging'ombe District Medical Officer, and women's attended makambako $\mathrm{RCH}$ for granting us the permission to conduct our survey and giving us full support needed to complete our study successfully.

\section{REFERENCES}

1. Whitaker AK, Johnson LM, Harwood B, Chiappetta L, Creinin MD, Gold MA. Adolescent and young adult women's knowledge of and attitudes toward the intrauterine device. Contraception. 2008 Sep 1;78(3):211-7.

2. Greenberg KB, Makino KK, Coles MS. Factors associated with provision of longacting reversible contraception among adolescent health care providers. Journal of Adolescent Health. 2013 Mar 1;52(3):372-4.

3. van der Westhuizen N, Hanekom G. Patient knowledge about and intention to use the intrauterine contraceptive device (IUCD) at a tertiary-level hospital. South African Journal of Obstetrics and Gynaecology. 2016;22(2):42-6.

4. Taapopi, F.N. "Exploring the knowledge, attitudes and practices regarding the Intrauterine Contraceptive Device (IUD/IUCD) among family planning acceptors and providers in Khomas region, Namibia." $\mathrm{PhD}$ diss., University of Namibia, 2016.

5. Lopez-del Burgo C, Mikolajczyk RT, Osorio A, Carlos S, Errasti T, De Irala J. Knowledge and beliefs about mechanism of action of birth control methods among European women. Contraception. 2012 Jan 1;85(1):69-77. 
6. Yemaneh Y, Birie B. Assessment of knowledge, attitude and utilization of long acting family planning method among women of reproductive age Groupe in Mizan-Aman Twon, bench-Majizone, south West Ethiopia, 2016. Integr J Glob Health. 2017;1(2).

7. Ntezimana J, Niragire F. Socio-economic and demographic factors associated with use of contraception in Rwanda.

8. Ghiselli, M.E. "The effects of family planning type and prevalent use on fertility and under-five mortality in Tanzania." (2012).

9. "2002 Population and Housing Census General Report". National Burean of Statistics of Tanzania, accessed via GeoHive. Archived from the original on March 11, 2012. Retrieved October 24, 2010.

10. Whitaker AK, Terplan M, Gold MA, Johnson LM, Creinin MD, Harwood B. Effect of a brief educational intervention on the attitudes of young women toward the intrauterine device. Journal of pediatric and adolescent gynecology. 2010 Apr 1;23(2):116-20.

11. Frank, M.L., Poindexter, A.N., Johnson, M.L. and Bateman, L., 1992. Characteristics and attitudes of early contraceptive implant acceptors in Texas. Family Planning Perspectives, pp.208213.

12. Builu PM, Naidoo TD. Attitudes towards and knowledge about intrauterine contraceptive devices among women in the reproductive age group in a resourceconstrained setting. South African Journal of Obstetrics and Gynaecology. 2015;21(2):27-32.

13. Gutin SA, Mlobeli R, Moss M, Buga G, Morroni C. Survey of knowledge, attitudes and practices surrounding the intrauterine device in South Africa. Contraception. 2011 Feb 1;83(2):145-50.

14. Kinyanjui, J.N., 2016. Determinants of Iud Uptake in Kiambu and Machakos County (Doctoral dissertation, University of Nairobi). 
15. Berenson, A.B., Tan, A. and Hirth, J.M., 2015. Complications and continuation rates associated with 2 types of longacting contraception. American journal of obstetrics and gynecology, 212(6), pp.761-e1.

16. Somba, M.J., Mbonile, M., Obure, J. and Mahande, M.J., 2014. Sexual behaviour, contraceptive knowledge and use among female undergraduates' students of Muhimbili and Dar es Salaam Universities, Tanzania: a cross-sectional study. BMC women's health, 14(1), p.94.

17. Patterson RL. Improving family planning in Pakistan: Lessons learned from Iran. Dartmouth College; 2013. 